Chapter 2.

\title{
Content-based instruction as the constituent part of the constructivist approach that determines the selection of the content of teaching/learning English for Specific Purposes at tertiary schools
}

Content-based instruction is the second (out of three) fundamental notion underlying the constructivist approach advocated in this monograph. But if the first fundamental notion (experiential interactive teaching/learning) mostly concerns the methods involved in such teaching/learning, content-based instruction refers to the content of that teaching/learning, to the selection of that content, and to the phases in ESP teaching connected with transitions from the simpler to more sophisticated forms of instruction where the content matter of professional disciplines/activities, and not the language, is in the focus of attention. All these issues require a detailed analysis.

1. Content-based instruction: its definition and relation to experiential learning

One of the first and most thorough analyses of content-based instruction was made in the work by Brinton, Snow, \& Wesche as far back as 1989. Summing up everything that was said about it in their book, the following definition of content-based instruction (specifically adapted to ESP by us) can be suggested:

Content-based instruction is the integration of content from the subjects of students' majors with the goals of target language teaching. It ensures parallel acquisition of knowledge from certain non-linguistic disciplines together with acquisition of the target language and the skills of communicating in it. In such instruction, the ESP curriculum is most closely linked or even based on the curricula of one or several of students' majoring disciplines so that learning the target language content follows the requirements of learning some professional content from the majoring disciplines through the medium of the target language. The development of students' target language communication skills proceeds mostly 
subconsciously through their learning in the target language the content matter from the majoring subjects. In this way, content-based instruction eliminates the gap between language learning and learning professional subjects ensuring students' learning the latter through the medium of the former.

From this definition, it becomes clear how closely linked to experiential learning (or rather to the experiential interactive learning discussed in Chapter 1) content-based instruction is. In both cases, target language learning/acquisition proceeds mostly subconsciously - in the first case (experiential learning), through modeling professional activities in the process of which professional communication in the target language is going on; in the second case (contentbased instruction), through modeling professional content matter of nonlinguistic academic disciplines in the language classroom. It may be said that experiential learning and content-based instruction complement each other - just as learning methods and learning content are mutually complementary.

Despite this closeness, experiential learning and content-based instruction can exist and be implemented separately. If experiential learning is organized at a secondary school, it need not necessarily be content-based. For instance, the content of students' role play, presentations, and even project work can be taken from everyday life, i.e., there can be no connection with any specific academic subject or profession. On the other hand, when Brinton, Snow, \& Wesche (1989) were writing about content-based instruction procedure, they did not mention experiential learning in any way. So, the former is, in principle, possible without the latter.

However, such 'separate existence' of experiential learning and content-based instruction ceases when ESP is being taught at tertiary schools, at any rate, if that teaching is based on experiential teaching/learning procedures. In tertiary school ESP courses, experiential learning is totally impossible without contentbased instruction. This is because otherwise (when teaching English is not based on the professional content, i.e., on the content of students' professional majoring disciplines) the very sense and essence of teaching English for specific/ professional purposes will be irretrievably lost. From this point of view, the relations between experiential teaching/learning and content-based instruction in tertiary school ESP courses can be represented as they are shown in Fig. 5: two intersecting ovals in which the joint part is experiential interactive content-based ESP instruction at tertiary schools.

From what is shown in Fig.5, it is clear that experiential interactive contentbased ESP instruction at tertiary schools is supposed to meet all the requirements both of experiential learning (c.f. Chapter 1) and content-based instruction. In fact, those requirements are quite similar if not totally identical, so there is no problem in trying to meet them when they are brought into play together. For instance, Brinton, Snow, \& Wesche (1989) emphasize that in content-based instruction only those learning activities are acceptable that are specific for the 


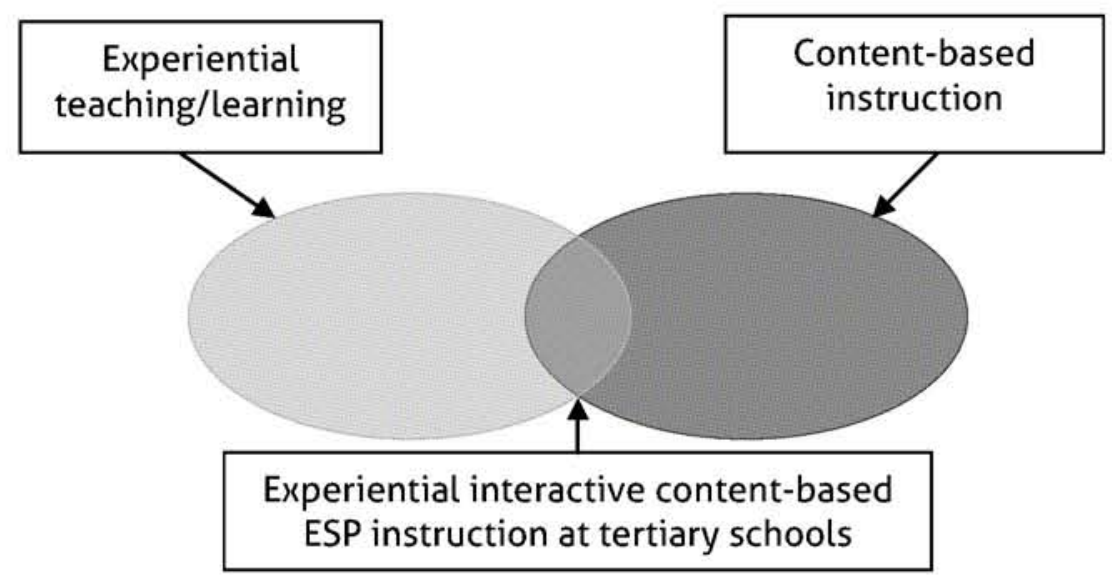

Fig. 5 The relations between experiential teaching/learning and content-based instruction in tertiary school ESP courses

professional content taught through the medium of the target language. But it is the same for experiential learning in which only those learning activities are used in the classroom that model or imitate professional activities, while the activities that are language forms-focused may be allowed only out of class (c.f. Chapter 1). This again emphasizes the closeness, even kinship, of experiential learning and content-based instruction and the rationality of using them together in the framework of one and the same approach to ESP teaching at tertiary schools.

It is only in the indivisible unity of experiential interactive teaching/learning and content-based instruction (experiential interactive content-based ESP instruction) that the constructivist approach can be practically implemented in tertiary school ESP courses. But this aspect deserves a separate analysis.

\section{Experiential interactive content-based ESP instruction as practical implementation of the constructivist approach}

To explain why it is experiential interactive teaching/learning and content-based instruction that only in their unity can ensure the practical implementation of the constructivist approach to designing tertiary school ESP courses, it is necessary to discuss the fundamental characteristics of every constructivist learning environment (including the ESP learning environment). Such characteristics 
were most fully described by Jonassen (1995). The list of constructivist learning environment's characteristics suggested by that author (with our comments concerning ESP) is given below. According to the list in question, the ESP constructivist learning environment must be:

1. Active - Learners are engaged in mindful processing of the information and are responsible for the result of such processing. To achieve that in ESP courses, the information has to be meaningful and significant for learners, i.e., professional, and this is ensured by the content-based instruction, while experiential interactive learning ensures mindful processing of the information supplied to learners. Thus, the unity of experiential interactive learning and content-based instruction provides for the implementation of the first characteristics of the constructivist approach.

2. Constructive - Learners incorporate new ideas into prior knowledge to solve particular issues or problems. In ESP it means the requirement to make learners face professional problems or issues that only contentbased instruction can provide, while only experiential interactive learning can develop fully adequate procedures for solving such problems/issues on the basis of prior knowledge and through the target language medium (again the unity mentioned above).

3. Collaborative-Learners mostly work not individually but in communities that have learning and knowledge building as their goals. In such communities the knowledge and skills of every member are exploited by all the other members of the community, and that community observes and evaluates the contribution of each of the members providing all of them with social support. This feature of the constructivist approach is implemented in ESP through experiential interactive learning, or rather through its interactive component, while the content-based instruction (in unity with experiential interactive learning) provides learners with the professional materials on the foundation of which the learning community builds new knowledge and skills.

4. Intentional-Learners have a common intention of achieving the learning goals. In ESP, experiential learning ensures the emergence of students' process motivation (c.f. Chapter 1) for generating such an intention, while content-based instruction in unity with experiential learning reinforces that intention by channeling it towards achieving professional goals through target language learning.

5. Conversational-Learning is a social, dialogical process by its very nature, so it is from dialogical/conversational learning in knowledge-and-skillbuilding learning communities that learners benefit most. In ESP, the conversational types of learning activities, which characterize experiential learning (role plays/simulations, discussions, presentations, etc. - c.f. 
Chapter 1), provide for the practical implementation of this feature. Those activities achieve the required conversational effect not alone but in unity with content-based instruction providing for the professional content of students' dialogical target language communication.

6. Contextualized-Learning tasks are designed as meaningful real-world or simulated/modeled real-world tasks and are problem-based. This feature of the constructivist approach is at the same time the most prominent feature of experiential learning while (in unity with it) content-based instruction provides for the professional nature of such learning tasks making them appropriate for an ESP course.

7. Reflexive - Learners articulate what has been learned by them and reflect on their decisions and the processes through which they have arrived at those decisions. Every experiential learning activity discussed in Chapter 1 is built on just such articulation and reflection, while content-based instruction ensures the appropriateness of experiential learning activities for an ESP course by filling those activities with professional content.

As it can be seen from the comments above, experiential interactive learning and content-based instruction genuinely and practically make an ESP course a constructivist one - but only in their unity, i.e., if they are used together in total harmony, while using only one of them cannot ensure the same effect. An identical conclusion can be arrived at if the seven constructivist principles in language learning put forward by another author - loannou-Georgiou (2002) - are quoted. According to her, constructivist learning is supposed to:

- "be an active process

- occur in authentic, interesting, and meaningful contexts

- take place in whole activities, such as projects, and not isolated skills exercises

- be context-dependent (e.g., activities should be linked around a situation or topic in which students are interested)

- be related to out-of-school experiences

- involve collaboration

- involve social negotiation of knowledge" (loannou-Georgiou, 2002: 21).

Three of loannou-Georgiou's principles of constructivist language learning - being an active process, occurring in authentic, interesting, and meaningful contexts, and involving collaboration - fully coincide, even in name, with three out of seven Jonassen's characteristics of the constructivist learning environment: to be active, collaborative, and contextualized. So, there is no need to prove additionally that the unity of experiential interactive learning and content-based instruction meets the requirements of those three principles in a constructivist ESP course since that has already been proved. The principle of involving social negotiation of knowledge, though 
different in name, means absolutely the same as one of the characteristics of the constructivist learning environment that Jonassen (1995) called the conversational feature of that environment. So, in this case, additional proof is not needed either. But the fact that the unity in question also meets the requirements of the remaining three principles is also easy to prove following a similar line of argumentation as above.

Thus, for instance, the principle of context-dependency (linking activities around a situation or topic in which students are interested) is met by content-based instruction because just that kind of instruction is responsible for selecting professional topics and situations interesting for students and important for their professional development. But it is experiential/interactive teaching/learning that is responsible for profession-oriented work with the topics and situations selected so that their use inside and outside the language classroom would become beneficial both for students' progress in target language acquisition and for their professional growth (ESP).

The constructivist principle of learning in whole activities, such as projects, and not isolated skills exercises, is also a fundamental one for experiential interactive learning that, as follows from everything said in Chapter 1, is completely based on the whole language approach (Barclay, \& Boone, 1993; Blake, 1990; Goodman, Goodman, \& Hood, 1989; Manning, \& Manning, 1989; Stice, Bertrand, \& Bertrand, 1995; Wolsch, \& Cothran Wolsch, 1982). The experiential learning activities, such as project work, continuous simulations, case studies, discussions, and all the others require the involvement of all the four communication skills: speaking, reading, listening, and writing (c.f. Chapter 1), i.e., are designed following the whole language approach, and not isolated skill exercise approach. But what content matter is processed in those activities depends on the selection process regulated by content-based instruction. That is why, again, only the unity of experiential interactive learning and contentbased instruction allows meeting the requirement of the principle in question in the conditions of ESP teaching and learning.

Finally, the principle of relation to out-of-school learners' experience is met by the interactive component of the experiential interactive learning, namely, the interaction with outside professional target language environment/outside professional target language sources of information, while it is the responsibility of content-based instruction to determine what kind of professional environment/professional target language sources of information are required in each particular case. This is just another example of the necessity of using experiential interactive learning and content-based instruction in their unity to meet the principles of the constructivist approach.

Whatever other, out of very few, publications devoted either to the constructivist approach to language teaching/learning (Norman, 1998; Opp- 
Beckman, 2002; Sotillo, 2002) or to the constructivist approach in general (Jonassen, 1991a, 1991b) are taken for analysis, the result will be same: everything the authors of those publications believe to be important for constructivist teaching/learning is ensured in ESP courses by the unity of experiential interactive learning and content-based instruction - but only by their unity and not by each of them separately. In this tandem both components have an equal responsibility and equal significance for implementing the constructivist approach to ESP courses - just as it is shown in Fig. 6.

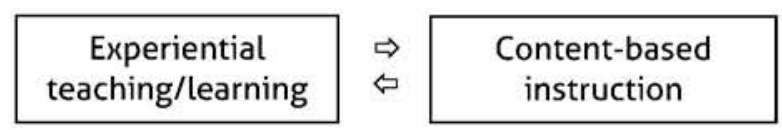

Fig. 6 The relations between experiential teaching/learning and content-based instruction as two equally significant constituent parts when implementing the constructivist approach to an ESP course

Therefore, everything said above shows that in ESP teaching/learning at tertiary schools the practical implementation of the constructivist approach becomes possible on the basis of introducing experiential interactive teaching/learning and content-based instruction - the first being responsible for the learning activities that are used, while the second is responsible for the selection of materials for the teaching/learning process. As it will be shown in Chapter 3, the third component of the approach suggested in this monograph, blended learning, is not as important as the first two, being subordinate to them and serving for the optimization of their practical implementation. But, in principle, a constructivist ESP course at tertiary schools can be designed even without blended learning, only on the basis of experiential teaching/learning and content-based instruction.

Having determined the relations between the experiential teaching/learning and the content-based instruction in a constructivist ESP course, it is most important to analyze how the latter - the content-based instruction -allows for the selection of the learning content for such a course. This should be done in the same way as in Chapter 1, where it was shown how experiential teaching/ learning determined the practical learning activities to be used for ESP. But, before starting such an analysis, which is required for discussing the principle subject matter in this chapter, some other aspects concerning content-based instruction need to be considered. Since content-based instruction exists in different versions known under different names and has some other approaches closely related to it, it is first necessary to analyze those modifications and decide which of them is most suitable for an experiential interactive ESP course suggested in this monograph. 


\section{Versions of content-based instruction and approaches closely related to it}

Content-based instruction has become widespread and enjoys great popularity in teaching English in the countries of Europe and North America. Evidence of this can be seen in the fact that entire collections of works have been published summarizing teachers' experiences in using content-based instruction in their pedagogical practice (c.f., for instance, Brinton, \& Master, 1997).

It should be noted that in recent years content-based instruction has been known in Europe under the name of CLIL (Content and Language Integrated Learning) and there it has certain peculiarities that make it a version of one and the same approach. This version should be considered first.

\subsection{Content-based instruction and CLIL as its broader version}

The only difference between content-based instruction and CLIL is that CLIL is interpreted as a wider notion. (From this point of view, it is content-based instruction that should be considered a version of CLIL and not vice versa, though the former was developed earlier than the latter.) According to Marsh (2002: 15), every kind of language learning in which a target language is also used for teaching students non-linguistic content can be called CLIL, so that CLIL is an umbrella term for all such dual-focused educational contexts (Coyle, 2007: 97). It is this broad interpretation that determines the above-mentioned peculiarities of CLIL as compared with content-based instruction.

CLIL includes a much broader complex of various approaches than contentbased instruction does because it is not specifically oriented at ESP and adult education, as the latter one is; it is no less, if not more, oriented at secondary school and the language education of adolescents (Eurydice Report, 2006). This, no doubt, requires specific methodological solutions and specific, as compared to content-based instruction, modifications of the approach. Those modifications do not interest us because they mostly do not concern tertiary education. What does interest us is the general advantages of CLIL which embrace content-based instruction as well - as a narrower (oriented only at ESP and adult education) version of CLIL. Those advantages were formulated by Coyle (2007: 104-105) who has shown that CLIL (and correspondingly, content-based instruction) can:

- "Raise learner linguistic competence and confidence;

- Raise teacher and learner expectations;

- Develop risk-taking and problem-solving skills in the learners;

- Increase vocabulary learning skills and grammatical awareness; 
- Motivate and encourage student independence;

- Take students beyond 'reductive' foreign language topics;

- Improve L1 literacy;

- Encourage linguistic spontaneity (talk) if students are enabled to learn through the language rather than in the language;

- Develop study skills, concentration - learning how to learn through the foreign language is fundamental to CLIL;

- Generate positive attitudes and address gender issues in motivation;

- Embed cultural awareness and intercultural issues into the curriculum."

All these advantages of CLIL (and the advantages of content-based instruction as its narrower version) have led to the emergence of some ideas that have recently appeared in professional literature. Those ideas assert the inadequacy of ESP teaching in a more traditional manner when it is the language itself, or rather the professional sub-language, that is in the focus of teachers and students' attention (like in the approach developed by Robinson, 1991). For instance, Bicknell (2009) posed the question why we should teach Business English traditionally if CLIL can do it much more efficiently. Of course, not all authors agree with such ideas (c.f., for example, McBeath's (2009) objections to the article by Bicknell), but, in the conditions of CLIL (and content-based instruction) successes, their appearance seems inevitable.

It should be remarked that in the above controversy both sides are probably right - depending on the goals and conditions of ESP teaching and learning. For instance, if Business English, as one type of ESP, is being learned by practical businesspeople or economists who already know their field very well, no content-based instruction or CLIL is necessary since the students know the subject matter fully and do not need 'professional prompts' from their language course. Professional language is their only goal, so traditional ESP teaching of that professional language is quite adequate and sufficient. On the contrary, when ESP is taught to students who are not specialists in their profession yet, content-based instruction (or CLIL) is the best choice because it is just in this situation that all its advantages are most vividly manifested. Moreover, it seems quite probable that in future tertiary ESP courses content-based instruction (CLIL) may totally oust traditional language-focused teaching and learning.

Everything said above about the relations between content-based instruction and CLIL allows the following conclusions to be drawn:

1. Content-based instruction and CLIL are, in principle, if not identical, at least, very much similar. But CLIL is a broader notion. It includes different modifications, or versions, designed for different types of educational establishments, such as secondary schools, tertiary schools, etc., while content-based instruction is mostly aimed at teaching languages for professional use to adults, particularly at tertiary educational institutions. This is why, since this monograph deals with ESP at tertiary schools only, 
it is reasonable to call the component of the constructivist approach under consideration content-based instruction (but not CLIL) understanding it as it was interpreted at the beginning of this Chapter (c.f. 1). Therefore, the term CLIL will not further be used in the following pages for describing our approach.

2. Content-based instruction (like CLIL) has a number of advantages over language-focused ESP teaching/learning - those advantages that can considerably improve the results of teaching the target language for professional communication at tertiary schools.

3. Those advantages may cause gradual ousting of more traditional language-focused ESP teaching/learning procedures from tertiary schools and their total replacement with content-based instruction procedures.

The conclusions above reflect only the relations between content-based instruction and one of its broader versions - CLIL. But they say nothing about its relation to target language immersion that cannot be actually considered as a version of content-based instruction but, still, is quite closely related to it - especially in ESP situations.

\subsection{Content-based instruction and target language immersion as an approach closely related to it}

Teaching foreign languages through immersion has become a widely used practice both in North America and Europe after the success of the so called 'Canadian French immersion' (Calvé, 1991; Rehorick, \& Edwards, 1994). Every program of target language immersion is based on teaching some academic disciplines from the school or university curriculum in the language that the students are learning (Clark, 2000). More specifically, immersion programs for tertiary schools are defined as foreign language learning integrated with teaching other academic/professional subjects with the aim of providing students with the best means of acquiring their target language for professional communication (Walker, \& Tedick, 2000).

Some authors (Stoller, 2007) consider immersion as the supreme form of content-based instruction and there are, certainly, reasons to believe that this assertion is true because in both cases the focus of students and teacher's attention is on the content of an academic/professional discipline, while the target language (though also in some degree focused on in content-based instruction) mostly serves as a means of acquiring the knowledge and skills relevant to that discipline. However, we think that, though content-based instruction and immersion are very closely related, they are much too different to be considered as lower and higher levels of one and the same approach, and their relations are more of the kind shown in Fig. 7. 


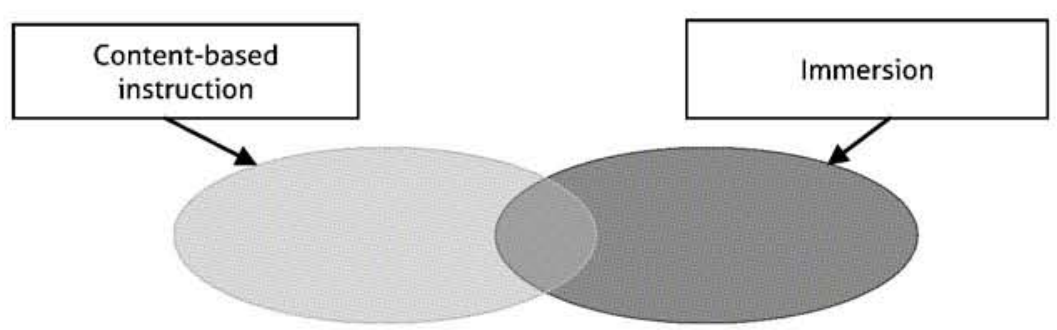

Fig. 7 The relations between content-based instruction and immersion

The difference between content-based instruction and immersion that, despite their closeness to each other, does not allow considering them as two levels of one and the same approach lies in the fact that, while content-based instruction belongs to a language course since it is done within classes in the target language, immersion belongs to a course of some non-linguistic discipline because it is in classes on that discipline, and not in language classes, that immersion is organized. This is why if in content-based instruction the teacher and students' attention can be focused both on content matter and on language in a more or less balanced manner (see 3.2. in Chapter 1), in immersion only the content matters while the target language is taken for granted. Thus, immersion is, in fact, outside the specific domain of second/foreign language purposeful teaching because language learning in it is totally based on involuntary acquisition and retention.

Therefore, what is discussed in this monograph (teaching ESP in classes of English at tertiary schools) is most certainly in the domain of content-based instruction, and not in the domain of immersion. But there is one aspect in the relations between content-based instruction and immersion that requires special consideration. This aspect is the issue of content-based instruction's (in ESP classes) contribution to later introduction of English immersion in classes on academic/ professional or majoring disciplines.

Immersion can be divided into several kinds (Tarnopolsky, Kozhushko, Zhevaga, 2010; Tarnopolsky, Momot, et al., 2008). The highest and the most complete kind of immersion is what is called total immersion (Johnson, \& Swain, 1997). Total English immersion is based on teaching classes on whatever academic/ professional subject not in students' L1 but in English. There is no 'adaptation' of the level of the English language in which the subject is taught to the level of students' command of English, which means that this latter level is expected to be high enough (at least, B2, if not C1 according to the Common European Framework of Reference-Council of Europe, 2001). More than that, such a high level of command of English should embrace not only (and not so much) General English but English for professional communication as well. 
Our research (Tarnopolsky, Momot, et al., 2008) has shown that if an ESP course at a tertiary school is designed in a traditional language-focused manner and is taught during two years (the first and the second years of university studies), as it is customary for Ukrainian higher schools where the research was done, it is impossible to introduce total English immersion in courses of other academic/ professional disciplines immediately after such an ESP course. Students' preparation and training in the English language will be absolutely insufficient for that.

However, this does not mean that in such a case introducing English immersion into tertiary school courses of academic/professional disciplines becomes totally impossible. But that introduction requires some specific measures directed at preparing students both linguistically and psychologically for 'total English immersion professional training'.

That issue was researched in the doctoral dissertation of our PhD student ( $Z$. Kornieva, 2004). She demonstrated that in the case under discussion total English immersion becomes possible in courses of academic/professional disciplines in the last year of students' university studies (the fifth year at Ukrainian universities) if, before introducing such total immersion and after the learners finish their traditional ESP course (after the second year of university studies at Ukrainian universities), students have not less than one year of sheltered immersion courses and not less than one year of partial immersion courses (the third and fourth years of university studies for the conditions of Ukrainian universities).

Sheltered/structural immersion (Cummins, 2000; 2001; Freeman, 2000; Kerper, 2004 ) is the lowest level and the simplest form of immersion. It is based on permanent but limited use of students' L1 in the English immersion classroom. For instance, lectures in the academic course can be delivered in students' L1 (with the lecturer obligatorily summarizing and briefly reviewing everything that was said by him/her in English at the end of every lecture). On the contrary, practical classes and seminars are held mostly in English, though occasional recourse to students' native language is not impossible. Papers written by students and all kinds of tests in the course are also held in English.

Partial immersion (Holobow, Genesee, Lambert, et al., 1983) is a higher level in immersion teaching and learning because it presupposes only temporary inclusion of students' L1 in an English immersion course of an academic discipline. For instance, lectures can be delivered in students' L1 at the beginning of the course, but gradually the lecturer passes on to lectures in English only.

On the one hand, Z. Kornieva's (2004) research has shown that even after a traditional language-focused ESP course, total English immersion in teaching academic/professional subjects at tertiary schools is quite possible if students approach that total immersion gradually, first through courses of sheltered immersion and then, through courses of partial immersion. But on the other hand, this research has also demonstrated that total immersion can be arrived at quite 
late (not earlier than the last year of students' university studies) and continue for quite a short period of time (not longer than one academic year) because the preceding immersion courses (sheltered immersion and partial immersion) take long enough - not less than an entire academic year for each of them.

It is due to that last shortcoming of the approach developed by Kornieva (2004) that a different approach to introducing total English immersion into university academic/professional or majoring courses has been developed by Tarnopolsky and his co-authors (c.f. Tarnopolsky, \& Kozhushko, 2005; Tarnopolsky, Kozhushko, Zhevaga, 2010; Tarnopolsky, Momot, et al., 2008).

The main idea of the approach developed by us for students of Economics and Business at Ukrainian universities was deliberate and purposeful learners' preparation for English immersion to be implemented later in their courses on academic/professional subjects. That preparation started in the second year of students' university studies in their ESP classes organized as experiential interactive content-based instruction on the basis of the coursebook Business Projects (Tarnopolsky, Kozhushko, et al., 2002). Such instruction was considered as direct learners' adjustment to the following immersion courses (preparatory immersion-c.f. Tarnopolsky, Momot, et al., 2008). Being not actually an immersion but content-based instruction because it was in classes of English and not in classes on academic/professional subjects, it was still closely related to future immersion since English for professional communication was being taught and learned mostly subconsciously through modeling students' future professional activities and professional communication in the target language when participating in such activities (c.f. Chapter 1). This allowed for both linguistic and psychological adjustment of students to their future English immersion studies (Tarnopolsky, \& Kozhushko, 2003: Tarnopolsky, Momot, et al., 2008).

The experiential content-based instruction in classes of English during students' second year of university studies served as a foundation for the introduction of what was called preliminary immersion in their third year (Tarnopolsky, \& Kozhushko, 2005; Tarnopolsky, Momot, et al., 2008). That was already a course of genuine immersion but slightly modified and facilitated in comparison with total English immersion. The course was designed as an intermediary form between an ESP course and a course on some academic/professional subject taught in English. It was organized as a series of mini-courses (18-20 academic class hours for every separate mini-course) on different disciplines in the field of Economics: Management, Marketing, Finances, Microeconomics, and some others. The minicourses, each of which was designed as a kind of simplified synopsis of a full academic course, or rather, as a kind of introduction to that course, were taught in English one after the other (four academic class hours per week - about five weeks for each of the mini-courses) all through the academic year. Each of the mini-courses was structured following the pattern of a regular academic course: with three or four two-hour lectures, four-five two-hour practical classes and/or 
seminars, and at least one two-hour class of final testing. As a result, on finishing a mini-course, students acquired a basic generalized knowledge of a particular academic subject through the medium of the target language, thus getting preliminarily prepared for a complete total English immersion course on that subject in the following academic year.

Such complete total English immersion courses were introduced beginning from the fourth year of students' university studies and could continue for two academic years (and not only one as in the case discussed before) - until graduation.

The fact that experiential interactive content-based ESP course and preliminary immersion course sufficiently prepared students for total immersion was due to their ensuring learners' gradual advance up the "stairway" of linguistic and psychological training that could let them relatively painlessly approach the highest and most difficult level of total immersion:

- on the level of experiential interactive content-based instruction there was some kind of balance between content matter focus and language focus (see Chapter 1), also there was some degree of students' psychological adjustment to future total immersion through modeling professional activities in their ESP classroom;

- on the level of preliminary immersion content matter focus considerably dominated as compared with language focus and students' psychological adjustment to future total immersion came to the forefront because the situation of total immersion was fully modeled;

- on the level of total immersion itself only the content matter of the academic course was in the focus of attention while the linguistic and psychological preparedness of students was taken for granted.

This model of introducing immersion courses - experiential interactive content-based ESP course (one academic year) $\rightarrow$ preliminary immersion course (one academic year) $\rightarrow$ total English immersion courses (at least, two academic years) - has been tested and tried at Alfred Nobel University. Dnipropetrovsk, Ukraine (including testing the model in experimental conditions) beginning from the year 2006 (Tarnopolsky, Momot, et al., 2008). It was demonstrated that even after their experiential interactive content-based ESP course students had mostly reached not only B2 level in their command of both General and Business English but were also well advanced towards level $\mathrm{C}$. That latter level was always achieved after the course of preliminary immersion, so that the following total English immersion was not of any excessive difficulty for students in what concerns the language, the psychological readiness, or the content matter. Moreover, there has been some evidence (though not confirmed experimentally as yet) that in many cases total English immersion could safely be introduced immediately after the experiential interactive content-based ESP course without the intermediary stage of preliminary immersion. That would allow devoting at 
least three years of university studies to teaching academic disciplines in the framework of a total English immersion program. Such findings have made it possible for the above mentioned university to make an agreement with the UK University of Wales concerning a joint program of teaching in English only future economists at Alfred Nobel University, Dnipropetrovsk with the aim of awarding the graduates two diplomas/certificates after graduation: the Ukrainian diploma/ certificate from Alfred Nobel University and the British diploma/certificate from the University of Wales. This program has been functioning successfully since 2010.

The extensive analysis above of the target language immersion at tertiary schools (though, in principle, such immersion is outside the scope of this monograph) was required to demonstrate one more important function of experiential interactive content-based instruction. It serves not only for substantially improving a university ESP course and making it most closely linked and related to students' professional training. It also serves for preparing students linguistically and psychologically for further English immersion in that professional training. But the efficiency of experiential interactive content-based instruction in fulfilling both of these functions depends on the adequate choice of a proper organizational form of content-based instruction for introducing it into the university experiential interactive ESP course as one of its leading components. This issue is analyzed below.

\section{Organizational forms of content-based instruction and their selection for an experiential interactive ESP course}

Brinton, Snow, \& Wesche (1989) distinguished three organizational forms of content-based instruction which were developed and described for teaching EAP (English for Academic Purposes) to international students learning English as a second language (and not as a foreign one - as is the case for this monograph) at US universities.

The first form is adjunct language instruction, the most advanced of all the three forms. Adjunct language instruction is a course of English accompanying what was called total English immersion above. It is organized for those international students at American universities who are taught their majoring subjects in mainstream courses together with American students but need some help to cope with their language problems in those mainstream courses. Adjunct language instruction is designed specially for rendering such help, so it cannot be considered as an independent language course. 
This kind of instruction can be used when English for professional communication is taught as a foreign, and not as a second language at tertiary schools but at a much later stage than the stage discussed in this monograph when students are just starting their ESP course. Adjunct language instruction is required only if and when total English immersion is introduced in courses on academic/professional disciplines during senior years of students' university studies. That is why it is not necessary to analyze such a kind of instruction in details in this monograph because it is beyond its scope.

The second form is sheltered content instruction. It was developed for those international students at American universities whose English (as a second language) was insufficient for attending mainstream courses on academic/ professional subjects together with American students. They have separate courses on those subjects organized for them only, and such courses are taught in English that is modified and simplified, i.e., specially adapted to the level of students' command of the language.

In the terminology of our monograph, this form is not a form of content-based instruction at all but a simplified (as to language) form of English immersion. This is because the language for professional communication is acquired not in language (ESP) classes but involuntarily in classes on some other academic disciplines. The place of sheltered content instruction is somewhere between what was called above preliminary immersion and sheltered immersion - as one more form of teaching and learning facilitating the students' transition from their ESP course to their total English immersion courses on majoring disciplines. Anyway, this organizational form is also beyond the scope of our monograph.

The third form which is of the greatest interest to us is theme-based language instruction. It is specially designed for ESP classes only, and not for some kinds of immersion teaching. The course of ESP, when it is built as theme-based instruction, is structured around a set of professional topics (themes) that follow each other in a logical consecutive order which corresponds to the order of studying those themes in an academic course of some majoring discipline or in courses on several such disciplines. In theme-based instruction special attention is paid to the integration of reading, speaking, listening, and writing for professional purposes in the teaching/learning process (Brinton, Snow, \& Wesche, 1989).

No special proof is needed to assert that it is the theme-based language instruction which is the optimal organizational form for an experiential interactive content-based ESP course. First, it is the simplest form best suited for the conditions when the students only start learning ESP in their classes of English at university. Second, for an ESP course to be divided into professionoriented topics (themes) is absolutely logical and fully corresponds to students' (and teachers') expectations, so that they are psychologically ready for it. Finally, all ESP courses (even the most traditional and language-focused 
ones) have always been theme-based - meaning that they have always been divided into profession-oriented topics. (A different thing is how those topics are selected, arranged, studied, etc. - this is where the borderline between a traditional ESP course and a content-based ESP course lies). Such themebased division has always been recognized as highly pertinent to the learning purposes, so there is no need to reject it even if the course is different in a lot of other aspects.

One more feature that makes the choice of the theme-based form attractive is the fact that, as follows from what was said about experiential learning activities in Chapter 1, they are always task-based. And solving learning tasks in target language instruction is, according to Legutke, \& Thomas (1991), invariably a theme-centered interaction, i.e., requires theme-based organization.

Therefore, the organizational form of content-based instruction most suitable for the conditions of the experiential interactive content-based ESP course discussed in this monograph is the theme-based instruction. This may be considered as the general conclusion from everything said and analyzed in this section and the one that precedes it (devoted to English immersion in ESP teaching at tertiary schools).

The materials and analysis in these two sections allow admitting and stating (just like Stoller did in 2007: 59) that content-based ESP instruction together with English immersion, which is closely related to it and may follow it at tertiary schools, can be implemented through a number of their alternative and consecutive forms and configurations, such as the ones shown in Fig. 8 (the orientation is from the lower to the higher levels). These forms and configurations primarily differ as to the degree of their difficulty and sophistication that is mostly due to the degree of focusing on language in each of the forms or configurations: from the highest degree of such focusing in a traditional ESP course to its practically total absence in total immersion.

It is only the degree of language focusing that determines the rational consecutive order of proceeding from the lower forms/configurations to the higher ones - in accordance with the decrease of language focusing in each of the following forms/configurations, so as to gradually bring students to the level where their command of the target language is taken for granted (total immersion). As a result, a definite continuum shown in Fig. 8 appears.

From the scheme, it can be seen that traditional language focused ESP teaching/learning, having no relation by itself either to content-based instruction or to immersion, can yet, as experimentally proved (see above), lead to the total immersion through the stages of sheltered and partial immersion. Most probably, the transition may be facilitated if sheltered content instruction precedes entering the sheltered immersion stage and if the total immersion is aided by adjunct language learning - though this still remains to be tested in teaching practice. But in all cases, the road from traditional ESP to total English immersion 


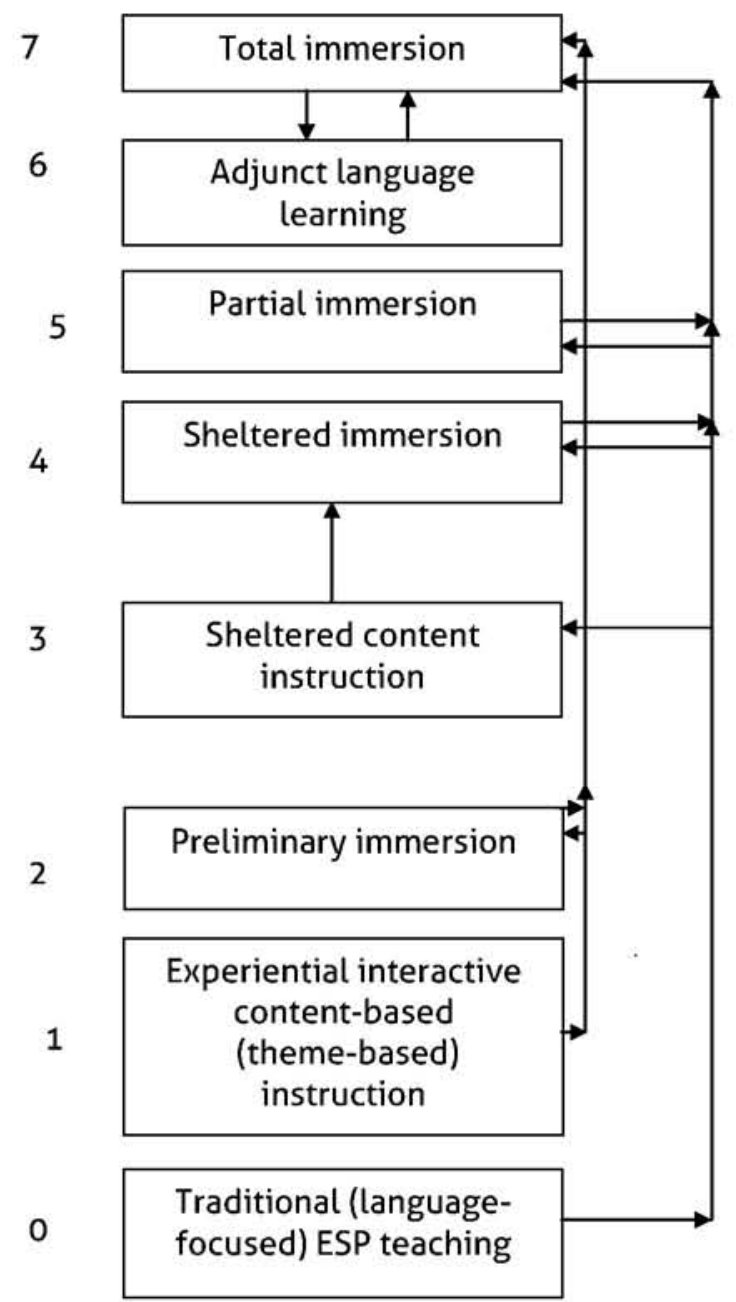

Fig. 8 The continuum of consecutive transitions from the simplest (bottom) to the most complicated (top) forms of content-based instruction and ESP immersion

is long and arduous, and when the final stage (total immersion) is reached at last, there is not much time remaining to practice it in the course of students' university studies.

The royal road to total immersion lies from experiential interactive contentbased (theme-based) instruction that, passing through only one intermediary stage of preliminary immersion (which, quite probably, may even be 'leapt over' - see before), directly leads to total English immersion that can be practiced dur- 
ing several years of students' university studies. Of course, in this case too total immersion can be aided by adjunct language learning, but, as shown in our research (c.f. Tarnopolsky, \& Kozhushko, 2005; Tarnopolsky, Momot, et al., 2008), the system may well work without it.

The general conclusion from everything said in this and the preceding section may be as follows:

For practical introduction of content-based instruction in the framework of the constructivist approach, the theme-based organizational form of that instruction is the most suitable one for use at an early stage of teaching ESP to tertiary school students. Using this form means structuring learning around professional themes (topics) selected in a definite manner and logically/consecutively following each other in the teaching/learning process. Using this form during the early period of ESP teaching and learning opens the road to introducing the total English immersion into courses of academic/professional disciplines in later periods of students university studies.

The conclusion above poses the question of what 'the definite manner' of selecting professional themes (topics) is and should be. That particular question, finally, directly brings us to the central issue of this chapter - the issue of selecting the content of learning for an experiential interactive content-based ESP course that embodies the constructivist approach to ESP teaching and learning at tertiary schools. The issue of learning content selection is analyzed in the next two sections.

\section{Learning content selection in an experiential interactive content-based ESP course}

The learning content is one of the three fundamental categories of second/ foreign language teaching/learning. (The other two have already been discussed in this monograph. The first is the goal of teaching/learning, this goal being, as mentioned, developing students' communicative competence in the target language - linguistic, sociolinguistic, and pragmatic (Council of Europe, 2001) for ensuring their efficient communication in that language. For the conditions of an ESP course, this communicative competence should be aimed at professional communication only. The second category is the method of teaching and learning, and entire Chapter 1 in the monograph is devoted to analyzing what kind of method is required if the constructivist approach to ESP is being implemented.) Hardly any proof is needed to assert that it largely depends on the properly selected learning content whether the goal of ESP teaching/learning will really be achieved. It also depends on the selected content how the method of teaching/learning is going to be implemented in the practical teaching/learning 
process. But to discuss the issue of adequate selection of the learning content, it is first of all necessary to specify what components this content consists of and what the general sequence of their selection should be.

\subsection{The componential structure of the learning content in an experiential interactive content-based ESP course and the general sequence of its selection}

There can be and are different ideas as to that componential structure but there hardly can be any objections to the statement that the learning content in ESP courses must include everything that the students are expected to retain in their memory after they finish their particular course. From this point of view, the components in question may be considered as consisting of:

1. Communication and language skills as the principal component of ESP learning content (since it is just such skills that make up the communicative competence which is the goal of teaching and learning). It should be noted that from what has been said before it is clear that communication skills that students are expected to develop embrace all the four basic communication activities (speaking, reading, listening, and writing), insomuch as those communication activities serve professional activities implemented through professional communication. But the situation with language skills is different. The development of learners' vocabulary skills is constantly in the focus of teacher and students' attention, while pronunciation skills are only subconsciously reinforced thanks to students' continuous participation in professional communication in the target language. Grammar skills are paid more attention to than pronunciation skills but mostly those skills are also just reinforced on the basis of what the students have achieved during their pre-ESP stage of English training (see Chapter 1, 3.2.).

2. Language materials. vocabulary, grammar, and pronunciation materials that students are supposed to retain in their memories because it is only when having those materials at their disposal, they can develop relevant vocabulary, grammar, and pronunciation skills. It should be noted that for an ESP course, only the vocabulary to be acquired by students is supposed to be properly and thoroughly selected. Pronunciation materials (pronunciation patterns) are not selected at all because all students' pronunciation skills are expected to be developed before their ESP course even starts, and the skills that are subconsciously reinforced in that course are only those that are activated when learners are orally communicating on some professional issues. The same concerns the greater part of grammar materials in an ESP course, though there may be some grammar in it that is new for students and that is selected exclusively in accordance with profession- 
al communication needs and processed according to the mode discussed in Chapter 1, 3.2. But this kind of grammar material is quite limited.

3. Sociolinguistic and pragmatic information that serves for developing students' sociolinguistic and pragmatic competences and relevant skills that are proper to the speech community (Hymes, 1974) whose language is being learned as the target one. In some cases, the sociolinguistic and pragmatic information from some other (not only the target one) speech communities may be included in the ESP course when it is known in advance that, after graduation, former students are going to communicate in English with representatives of a number of different cultures. This is especially characteristic of Business English studies. In general, owing to the growing intercultural and cross-cultural orientation of language teaching and learning, the adequate selection of sociolinguistic and pragmatic information for such teaching and learning has an ever-increasing significance for evaluating an ESP course as quite suitable.

4. Speech/communication materials and samples, such as professional texts for reading, audio and video materials, etc. These materials are included into the learning content not because it is expected that students retain in their memories every single professional text in English that they have read or very single professional conversation in English that they were listening to in their ESP course. But, first, it is expected that they retain the content information from those materials because only on the basis of that information their own speech production in English is possible. (Students in an experiential interactive content-based ESP course often get professional information in their ESP classes before they obtain it in their classes on academic/professional subjects. This is why the professional texts and audio/video materials in English are frequently the only sources for them to obtain such information and generate their oral and written speech in English on its basis. Therefore, the information in question necessarily has to be retained in students' memory.) Second, it is mostly those materials that are the sources of vocabulary, grammar, sociolinguistic and pragmatic information that must be retained by students (see above), so they also need to be at least partially retained in their memories in what concerns the language, pragmatic, and cultural data from them.

5. Themes (topics) and situations for communication. This is the last component, but not the least important. First, this is because if an ESP course under discussion is theme-based, it is clear that professional themes (topics) to be studied in the course must be carefully selected for achieving the course goals. Second, no communication (either professional or not) is possible without a topic. Actually, communication starts with a certain topic (theme), which determines the communication content. Though in the process of every kind of communication topics may be changed, each of the 
single fragments of verbal intercourse is always devoted to some specific topic and cannot take place in its absence. The same concerns situations because no communications, either spoken or written, is possible outside some situation in which that communication is developing (Zimniaya, 1985). One and the same book of fiction will be read differently if we are reading it for relaxing while lying on the sofa or while revising for an examination on literature, i.e., depending on a particular situation. In the same way, one and the same professional topic will be discussed differently in the situation of a professional meeting and in the situation of having lunch together with a colleague. This means that 1 ) in their interaction topics (themes) and situations of communication determine the communication content and, therefore, the characteristics of oral and written discourses (texts) generated and read/listened to in that communication; 2) through the content of communication and the characteristics of oral and written discourses (texts), those themes and situations determine the sociolinguistic and pragmatic skills that need to be used by communicators, the skills in question being developed in target language studies on the basis of relevant sociolinguistic and pragmatic information; 3) the themes and situations also determine the language material (like vocabulary) to be used by communicators; 4) finally, they determine the communication and language skills to be activated in this or that fragment of communication. This demonstrates that it is the themes (topics) and situations of communication that to a large extent determine the selection of all the other components of learning content - those that are higher up in the hierarchy (see above). So, themes (topics) and situations of communication may be considered as the foundation-laying, basic component of that content. It is on the selection of just this component that the selection of all the other components depends. As to the question what should be selected first: the themes or the situations; for teaching target language professional communication (ESP), there can be only one answer - themes should go (be selected) first. It is not only because we have chosen the theme-based instruction as the starting point for developing our experiential interactive content-based ESP course. It is also because professional communication as such is mostly governed by themes (topics) of that communication while the situations in which it takes place are usually adapted to the needs of professional communication on a particular professional topic. This is why communication on professional topics (themes) can sometimes take place in very unlikely or even inappropriate situations - like the situation of a corporate Christmas party.

The list of learning content components given above and the suggested interpretation of each of the components, especially the last one (themes and situations), both show the direction towards rational sequencing and selection of those components. The approach to logical sequencing and practical 
implementation of that selection was developed by the Ukrainian scholar Skalkin (1989) and later elaborated in details in the monograph by Tarnopolsky, \& Kozhushko (2004).

According to Skalkin (1989: 47), learning content is a structure of several layers in which the ground layer is the communicative aspect including the meaning of language signs and the meaning of texts selected for learning purposes. The next layer higher up is the linguistic aspect including the entire language inventory selected for learning purposes. The topmost layer represents the psychophysiological aspect which embodies the process of acquiring the knowledge and skills that are necessary for target language communication.

Skalkin's approach is attractive because it creates a foundation for selecting learning content in a manner that has some theoretical and logical substantiation as to its sequencing and is not done in a frequently encountered totally empirical manner. With the empirical approach, the authors of textbooks, coursebooks, and other teaching materials (including the materials for ESP courses) often begin selecting the learning content with the language inventory (grammar and vocabulary) that they believe to be the most important for the target language acquisition. All the other aspects of learning content (topics and situations for communication, texts for reading, audio and video materials, even skills that need to be taught) are selected so as to match and adjust them to the pre-selected language inventory. As a result, it is not communication and learners' communicative needs that govern the selection of language inventory but vice versa - the language inventory and the language system as a whole govern what kind of communication skills are taught to students. And this is definitely wrong from the point of view of the final teaching goal - developing students' communicative competence - that requires considering communication and communicative needs as the only governing factor regulating the selection of learning content in whatever kind of target language course.

This (regulating learning content selection through communication and communicative needs) is the approach suggested by Skalkin (1989). He postulated the communicative aspect as the starting point of such selection because it was defined as the bottom, initial, layer of that content. In the monograph by Tarnopolsky, \& Kozhushko (2004), it was shown that the communicative aspect of learning content includes the themes and situations of communication to be used in the teaching/learning process, as well as the speech materials and samples in which all the meanings of language inventory to be taught and learned must be found. The language inventory itself, as representing the linguistic aspect, includes the language materials whose selection was determined by the meanings of those materials selected on the communicative aspect level. The materials chosen on the communicative aspect level also regulate what knowledge (sociolinguistic and pragmatic) should be selected for students' acquisition. Finally, both the communicative and linguistic aspects determine what communication and 
language skills need to be chosen for acquisition and development by learners in the practical teaching/learning process.

The approach above suggested by Tarnopolsky and Kozhushko (2004) has led to postulating the logical sequence of conducting learning content selection for a content-based (theme-based) ESP course. This sequence is schematically shown in Fig. 9. According to the suggested sequence, first the themes (topics) on which the entire ESP course is based are selected and, on their basis and together with them, the situations for communication in the teaching/learning process. The selected themes and situations serve as the starting point for selecting typical speech materials and samples that cover the chosen themes and situations. Those materials and samples demonstrate what meanings of linguistic, cultural, and pragmatic units the students need for communicating in the framework of pre-

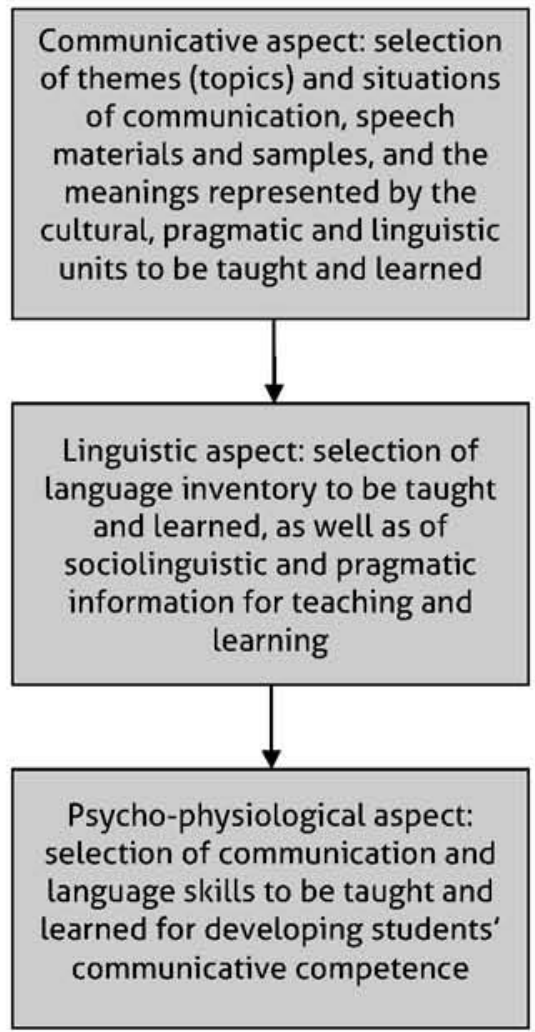

Fig. 9 The sequence of selecting the learning content for a content-based/theme-based ESP course (quoted from the work by Tarnopolsky, \& Kozhushko, 2004: 43) 
selected themes and situations. So, the materials and samples become the source for selecting the sociolinguistic and pragmatic information and language inventory. Finally, both the speech materials and the language inventory demonstrate what communication and language skills the students need to develop.

The advantage of such an approach to the selection of learning content for a content-based ESP course can be shown if the differentiation of the carriercontent and the real content suggested by Dudley-Evans, \& St. John (1998) is taken into account. Following these two authors, it should be said that carriercontent is the subject matter aspect of what learners read, hear, say, and write in the target language, while real content is the language and communication aspect of what they read, hear, say, and write in it. This latter aspect is always intrinsically dominant in whatever language course (by definition - because it is the language course), though its dominance may be hidden behind the seeming dominance of the subject matter aspect - like in content-based instruction. This seeming dominance is required when developing students' communicative competence is considered as the primary goal of teaching and learning since communication is always directed at and conditioned by its subject matter, and this to a much greater degree than it is directed at and conditioned by the language system. That is all the more true in what concerns professional communication taught in every ESP course.

Just for such a situation and approach, the above scheme of selecting the learning content for a content-based/theme-based ESP course seems to be the most suitable. This is because in the case under consideration the selection begins from the carrier-content (themes, situations, typical discourses/texts, etc.), and it is the carrier content that determines what real content (language units, communication skills, etc.) should be selected. This is the principal advantage that allows making the language instruction genuinely content-based.

Having determined the general sequence of implementing the suggested approach to learning content selection for a content-based/theme-based ESP course, the next step should be the detailed description of the full procedure of that selection.

\subsection{Procedure of learning content selection for an experiential interactive content-based ESP course}

\subsubsection{The first stage in learning content selection}

From the suggested general sequence of selecting the learning content for an experiential interactive content-based ESP course it is clear that selecting themes and communication situations is not only the first stage in the selection procedure. This is probably the most important stage just because all the 
following selection stages depend on it. This is why this first stage should be organized very carefully to obtain the most accurate and precise results.

Selecting themes (topics) as the first step, or stage, in the selection of learning content for a content-based ESP course, should be implemented following four basic conditions:

1. The selected themes should not embrace the most fundamental information about the content of just one, however important, students' majoring/professional discipline. They should reflect the fundamental content related to students' future specialty as a whole. Those themes are supposed to allow creating a kind of synopsis of learners' future profession in the target language. It is what content-based instruction is, in fact, designed for. Otherwise, the specific goal of every ESP course at tertiary schools cannot be attained. This goal is to prepare students for professional communication in the target language on all issues that may require such target language communication in the course of their professional activities and career. Achieving that goal is only possible if the students have a more or less complete 'picture' of their entire future profession formed through the medium of the target language; a 'picture' of just one academic discipline related to that profession cannot really help in attaining the required result. Thus, the selected themes are called upon to lay the foundation for creating a model of students' future profession in ESP classes.

2. The above condition presupposes that the themes for an ESP course should be selected from at least a number of students' majoring disciplines, if not from all of them. But all the selected themes need to be systematized and arranged in such a manner as to unite them into one integral and harmonious whole that can allow creating a model of students' future profession in ESP classes, or a synopsis (a short course) of that profession in the target language (see above).

3. The selected themes should be accessible and comprehensible to students. In all countries of the world where ESP courses are taught in the framework of tertiary schools' curricula, such teaching is, as a rule, planned for the first years of students' university studies (e.g., our ESP courses for future economists/businesspeople and future psychologists discussed and used as examples in this monograph were designed for students' second year at their universities). At that time, students do not know very much about their future profession as yet. But the fundamentals of that profession are quite accessible and comprehensible to them (in fact, the fundamentals of whatever profession are accessible and comprehensible to every layperson with a sound and complete secondary education). So, it is on such fundamentals that the selected themes should concentrate to make a content-based ESP course accessible to students during the given period of their university studies. Rendering all specific and more 
complicated professional details in the target language should better be postponed for later periods - for instance, when English immersion is introduced in courses of academic/professional disciplines (c.f. 3.2 and 4 in this chapter).

4. The task of selecting the themes for a content-based ESP course cannot be solved by ESP teachers, authors of textbooks, coursebooks, and other ESP teaching materials working totally on their own. These people are not and cannot be genuine specialists in any of the given fields of professional specialization, like Business Studies, Engineering, Biology, Psychology, Transport, etc., so they cannot select such themes in full accordance with the three requirements above in a fully competent and qualified manner. Collaboration with genuine specialists is required - and, preferably, not with just one or two of them but with at least several dozens, so that the themes are chosen following the opinions of their majority, thus providing for the most accurate and precise selection.

It is on the basis of the last requirement that we organized the selection of themes both for the coursebooks Business Projects for future economists and businesspeople and the coursebook Psychological Matters for future psychologists. In the first case, a kind of questionnaire was prepared with the list of fifty themes in the field of Economics and Business and distributed among 100 professional Ukrainian economists and businesspeople. Eighty of them were those who had a good knowledge of English and often had to use it in their professional activities (this was important for further selection of situations of professional communication that will be discussed below). Every participant of the survey was requested to tick 12 themes (the number of planned units for the coursebook Business Projects). They were those that he or she considered as the optimal ones to be chosen for most fully embracing the fundamental content matter of the majoring/professional disciplines in the field of Business Studies, so as to create for students a more or less complete, accessible, and comprehensible model of their future profession in the target language. Besides, every respondent had an opportunity of adding those themes that were not in the list but that s/he deemed to be important. The themes included in the final list of them (given further) were only the ones marked by no less than 75 respondents $-75 \%$.

An absolutely identical approach was followed when selecting the themes for the coursebook Psychological Matters, though in the latter case we managed to involve only 40 respondents, specialists in practical psychology, in our survey. As a result, the topics selected for teaching future psychologists in their ESP course comprised:

THEME 1. Psychology and its Branches

THEME 2. History of Psychology

THEME 3. Job Burnout

THEME 4. Balancing Work and Family 
THEME 5. Psychology of Employment and Working Place Conflicts

THEME 6. Managing Emotions and Feelings

THEME 7. Personality and Individual Differences

THEME 8. Psychotherapy

THEME 9. Gestalt Therapy

THEME 10. Psychological Counseling

After the themes for an ESP course designed for future psychologists had been selected, they were discussed (in the year 2008) with the scholars from the Department of Practical Psychology at Alfred Nobel University, Dnipropetrovsk, Ukraine (see also on that issue Chapter 4, section 1). That discussion confirmed that the themes really: 1) embraced the most fundamental information about the content of the profession of a practical psychologist, i.e., could serve as a basis for creating a synopsis (a short course) of that profession in the target language; 2) were sufficiently systematized as to their order of sequencing and arranged so as to make possible uniting them into one integral whole within a model of students' future profession that was supposed to be created in ESP classes; 3) were quite accessible and comprehensible for second year students of the Department of Practical Psychology as to the content matter that was expected to be discussed in the framework of those themes. Therefore, the themes in question fully met the pre-set requirements for their selection.

The procedure of selecting professional situations for communication, supposed to be chosen, as it follows from what was said before, after the themes and on their basis (to match them), had been quite similar to the one described above. When preparing both coursebooks Business Projects and Psychological Matters, the lists of fifty possible situations of professional communication in the target language were compiled, and the same respondents who took part in selecting the themes were asked to tick the communicative situations that matched the themes already selected by them. They were asked to tick only the situations that, in accordance with their personal experiences, were the most likely to occur in the conditions when a particular professional theme was the subject matter of communication in the target language. They also had opportunities of adding some situations that they considered as important but which were not included in the list that they had received.

This is why only those respondents who had good knowledge of English and often had to use it in their professional activities were involved. Thus, just eighty out of one hundred respondents taking part in the selection of professional themes for the coursebook Business Projects could participate in the process of selecting professional situations of communication to match the already selected professional themes - since only they had practical experience of using English for professional communication (see above). They chose the following situations of oral (speaking and listening) communication to match the earlier selected twelve professional themes: 
Themes:

Forms of Businesses

Company Structure

Making Appointments and Making Business Inquiries

Career Profiles and Applying for $a \mathrm{Job}$

Domestic and World Economy

Business Objectives, Strategies, and Competition

Marketing and Advertisements

Production

Banking

Finance

Participation in Fairs and Exhibitions

Contracts

\section{Situations:}

Businessinterviewing. Getting information concerning a particular company - for different purposes, like preparing for organizing a joint venture, preparing for starting a joint project, etc.

Business interviewing. Getting information concerning a particular company - for different purposes, like preparing for organizing a joint venture, preparing for starting a joint project, etc.

Business telephoning. Getting and supplying some required business information

Job interviews

Business and economic discussions. Business negotiations. Delivering business and economic presentations

Business and economic discussions. Business negotiations. Delivering business and economic presentations

Promotion campaigns. Business talks. Delivering business presentations

Business interviewing. Touring production facilities (factories, works, etc.) with different purposes, e.g. placing orders, company mergers, etc. Purchasing, selling, and delivering goods and equipment manufactured by an organization. Delivering business and economic presentations

Contacting banks with the aim of getting bank services, obtaining loans, opening accounts, etc.

Discussing company's finances, sales and sales results, etc. Discussing financing in a joint project. Delivering business and economic presentations

Business discussions, business negotiations when participating in and attending fairs and exhibitions. Delivering business presentations

Business discussions. Business negotiations. Purchasing, selling, and delivering goods and equipment manufactured by an organization. Delivering business presentations 
According to our respondents, specialists in the field of Business and Economics, this set of situations faithfully reflects the most probable and frequent cases in which a businessperson for whom English is a foreign language has a professional need to speak English and to listen to English being spoken. These situations are the most probable and frequent ones when a businessperson wants to discuss some business issues and solve some business problems with his or her foreign counterparts, and English is their only possible verbal medium of professional oral intercourse. Therefore, it is at the intersection of such selected topics and situations that typical speech materials/samples for teaching oral communication in English must be selected for an experiential interactive ESP course. (Those materials/samples are called upon to demonstrate how English is typically spoken in the selected situations when the selected topics determine the subject matter of communication.)

The same concerns written communication. For teaching reading and writing, situations are selected in an identical manner on the basis of and to match the pre-selected themes (e.g., the situations of reading the text of a business contract prepared as a result of business negotiations or the situation of preparing that contract in writing after discussing its clauses). Speech materials/samples for teaching written communication are selected at the intersection of those themes and situations.

\subsubsection{The second stage in learning content selection}

The selection of such materials/samples (texts for reading in English, audio and video materials, etc.) is, as follows from the scheme in Fig. 9, the second stage in selecting the learning content for an ESP course. The number of sources for that selection is practically unlimited. The largest store of authentic materials in English can be found on professional Internet sites. That concerns not only the materials for reading but also the materials/samples for listening (YouTube and other Internet media).

An instance of one of many Internet sites used by us when working on the theme "Managing Emotions and Feelings" for Unit 6 in the coursebook Psychological Matters (Tarnopolsky, Kozhushko, et al., 2011a) was http://EzineArticles.com where materials from different fields of knowledge (including Psychology) can be found. Some typical texts on the topic of emotions and feelings were there at that time, and they could be used as a source for creating teaching materials for profession-oriented reading in English on that subject. An example that can be given is an extract from the article by Zoey Jordan retrieved from the site in question January 11, 2009 (http://EzineArticles.com/?expert=Zoey_Jordan):

"A feeling has no power over you, unless you allow it to. Releasing allows us to get more in touch with our intuition. There is a difference between our intuition and our emotional reactions. The more releasing you do, the more intuitive you'll feel. 
Negative feelings cut us off from the flow of abundance, joy, excitement and creativity that we are entitled to experience. Sometimes the thought of releasing or letting go of the low energy emotions can feel overwhelming. Maybe we resist letting them go. Our rational mind knows that letting go or releasing the feeling will better serve us, but we might wonder "Who would I be without the feeling?»

If you wonder who you might be without the feeling, make a list. A simple list of pros and cons. If you do release the feeling - what might that feel like? What positive changes do you think you might experience? Do the same for holding onto the feeling - how is that feeling serving you?

Our emotions actually relate to each other in an organized way. Releasing will allow your mind to become progressively clearer. The changes you feel as you move out of low energy emotions might be gradual. But each time you go through the process of releasing, you will notice yourself naturally gravitating more to the higher energy emotions.

For example, apathy is an emotion that we feel each day to some degree. It would serve us to move through and release the low energy emotions so we can move into lighter, more positive feelings. Some examples of feeling apathetic might include feeling:

- Defeated

- Hopeless

- Indifferent

- Lazy

- Lost

- Numb

- Overwhelmed

- Worthless

Challenge yourself to take action when you least feel like it. Putting something into motion is the opposite of apathy. Taking action engages your mind in a lighter thought, and allows you to access a better feeling."

Speech materials/samples found on the Internet (like the material above) most certainly need some 'pedagogical processing' for using them as texts for reading or audio/video materials for listening in the teaching/learning process. (What kind of processing is required will be discussed in details in Chapter 4.) But on the other hand, the Internet has some really incomparable advantages as a source for selecting speech materials and samples. Those advantages are such that they make the Internet the principal source of speech materials' selection for content-based ESP courses. They are as follows:

1. The materials from the Internet are very accessible. Quite frequently, no special permission is required for using them for teaching/learning purposes (if the source and the author are duly quoted) because the copyright regulations in this case are often either absent or not so restricting 
as with the printed materials. This is especially true when the materials taken from the Internet have already been removed from it (This is the case with the fragment used above for giving an example).

2. Those materials are more than numerous; they are, for all practical purposes, unlimited in numbers and so varied and diverse that all requirements may easily be met, including the requirement to choose only those profession-oriented materials that are comprehensible to students in the early years of their university studies. Besides, it is only on the Internet that enough materials can be found to create a short synopsis (a short general course) of students' future specialty in their ESP classes.

3. The materials are authentic, i.e., prepared by native speakers of the target language for other native speakers; moreover, they are, as a rule, prepared by specialists in a given professional field. Both these factors are more than important if we want to create a genuine content-based ESP course (the course based on genuine professional content and not on the ideas about that content of an ESP coursebook writer who is not a real specialist in a given field). But to achieve this adequately, the selection of materials from the Internet should be done in cooperation between an ESP materials writer and a specialist in a given field of knowledge or a field of professional activities.

4. The numerous speech materials/samples found on the Internet can serve as the best source for selecting the language inventory and the sociolinguistic and pragmatic information - just because of the greatest possible volume of those authentic materials.

Of course, there are other sources that can be used for selecting the learning content at the stage of selecting speech materials/samples. For instance, textbooks on professional disciplines written for English-speaking students can provide a lot of authentic professional texts for reading in English. For future businesspeople annual companies' reports are a good source of reading materials too. Professional newsletters, magazines, and even specialized journals should not be neglected either as such a source. Even advertisements and promotional materials can help. But although the listed kinds of materials should never be discarded and, on the contrary, should be made the best use of, relying on them has several disadvantages:

1. Almost all printed materials (maybe, except annual companies' reports) are copyrighted, so that for using them, special permission is needed, which is not always easy to procure.

2. The printed materials in English are by far not as numerous as the materials that can be found on the Internet and those of them that are accessible to ESP teachers and teaching materials writers/compilers may simply be not sufficient for creating a short synopsis of students' future specialty in their ESP classes. In some countries or universities, such printed mate- 
rials may not be accessible at all or accessible in such small numbers as to be practically useless for creating a content-based ESP course.

3. Of course, the required printed sources can be ordered (e.g., through Amazon.com) and bought by ESP teachers and teaching materials writers/compilers. But buying them in sufficient numbers can often be too expensive not only for those teachers and writers/compilers themselves but even for their institutions.

4. Such sources are not as varied and diversified as Internet sources, so quite often it is difficult to find those of them that can fully meet all the requirements - like the requirement to choose only profession-oriented materials that are comprehensible to students in the early years of their university studies.

5. Because of their scarcity indicated above, printed materials may be insufficient for properly selecting the entire language inventory and the sociolinguistic and pragmatic information required for a content-based ESP course.

6. Last but not least, outside the Internet, it is very difficult to find enough audio/video materials/samples in English to provide for the needs of teaching listening in English for professional purposes (while on the Internet they are in abundance - if not actually recorded, then in the forms of tapescripts that can be recorded which amounts to the same as having recorded materials because, as said above, all the Internet materials need some 'pedagogical processing' before their inclusion into an actual ESP course).

This last difficulty can be overcome if the teaching materials writer/compiler collects his/her audio materials himself/herself by getting permission and recording some authentic samples of oral professional communication in English. Those (properly processed and re-recorded) samples may be used later in the audio supplements to printed coursebooks or in other teaching materials. This was the way followed by us for procuring the audio materials for the coursebook for future economists and businesspeople Business Projects (Tarnopolsky, \& Kozhushko, 2002). It was inevitable because at the time when the coursebook started to be prepared (in the 1990s) there was little possibility of getting audio/ video materials from the Internet. The initial recordings of such audio samples were made mostly in the USA but also in some other countries. Below, as an example, is a sample tapescript of a conversation recorded live (with the oral permission of its anonymous participants and their permission to use the recording further for learning purposes) in 1994 during the International Festival "Languages and Cultures" held in Moscow, Russia. This (later processed and rerecorded) conversation was used as one of a number of audio materials for Unit 11 in the coursebook Business Projects, that unit being devoted to participation of businesses in fairs and exhibitions (see the list of themes for the coursebook in 5.2.1.). 
The conversation is used in the ESP course based on the coursebook in question for teaching students listening to sample conversations that can be held in a company's booth at an international fair. The recorded conversation itself is being held between a company's representative (in this case, a representative of a language school from the UK) and a potential customer (in this case, a Russian parent who is interested in sending his daughter to that school for learning English). For convenience of reading, the tapescript below is presented without speech pauses, hesitations, silence fillers, etc. that were originally recorded:

A. Hello. I'm interested in your language school. Could you answer some of my questions, please?

B. Sure. Is it for yourself that you want to get the information?

A. No, it's for my daughter. I know English well enough. Will you please tell me where you are located?

B. Our school is located in the beautiful coastal resort of Torquay. That's in south west England. So, our students have an opportunity not only to learn the language, but also to relax at the seaside. That means studies and holidays together.

A. Fine. And what about accommodation for students?

B. Students live with families. They have bed, breakfast, and an evening meal. And living in families gives additional opportunities for language practice.

A. And what about lunch?

B. Students have to take care of their lunches themselves. But there is a small and quite inexpensive restaurant at school and lots of pubs in the neighborhood.

A. What courses do you offer?

B. We offer intensive courses in General English and Business English on a one-toone basis, or in small groups of 4-6 students. In small groups it is certainly cheaper.

A. How long are the courses? And how intensive? I mean, how many classes a day does that make?

B. The duration of the course depends on the student's choice. There are two-week courses, and one, two, or three-month courses. We also offer courses with a certificate. They last from 6 to 10 months. Some of them end with a test in General English, the others with a test in Business English. All our courses are intensive. That means that classes are held every weekday, five one-hour long classes a day.

A. And on weekends?

B. Weekends are for relaxing after studies. On some of them, tours are organized - to London, Salisbury, Stonehenge, and to some other places. On other weekends, 
there are sports competitions, dancing parties, and so on. Our students do not get bored.

A. What does the fee include?

B. First of all, the tuition fee. It includes not only classes, but also using the teaching materials, the language lab - in fact, everything needed for learning. Then, there is the board and lodging, paid separately. Finally, there is the cost of all leisure activities - tours, using facilities, and so on.

A. And what about the airfare?

B. That is not included. But transfers from the airport to the school and from the school back the airport after the end of the program are included in the cost of board and lodging.

A. Are there any discounts?

B. Yes, if you register and pay three months before the start of your program, you will get a discount. But the payment deadline is one week before our classes start.

A. Does the same teacher teach all the classes in one group?

B. No, we have 5 highly qualified teachers, all with an M.A. degree. They teach almost every group, but they teach different courses in the program. For instance, one teacher specializes in conversation practice, another teaches reading and writing, and so forth.

A. Could I have the application forms, please?

B. Sure. Here they are. And here's our brochure where you will find all the answers. I hope to see your daughter at our school.

\section{A. Thank you.}

This way of procuring audio materials for an ESP course, though possible and never to be neglected, is quite hard - finding people who would agree to have their professional communication in English recorded and would give permission to use those recordings in the teaching/learning process, ensuring that the oral recorded communication is really typical for the selected themes and situations, etc. For instance, it took us several years to collect and record all such audio materials/samples for the coursebook Business Project (Tarnopolsky, \& Kozhushko, et al., 2002) and the relevant content-based ESP course. Selection from the Internet resources when preparing the coursebook for future psychologists Psychological Matters (Tarnopolsky, \& Kozhushko, et al., 2011a) was much faster and less labor-consuming.

The above approaches to selecting speech materials/samples make such selection well-grounded and logical - ensuring the choice of only those materials 
and samples that are really authentic and typical for the pre-selected themes and situations of professional communication. The next logical step is, as already mentioned, the pedagogical processing of the selected speech materials/samples for making them ready to be used in teaching and learning. But this processing is outside the scope of learning content selection, so it will be discussed in Chapter 4 . In this chapter, the subjects for further discussion are the third and fourth stages in the process of content selection itself.

\subsubsection{The third and fourth stages in learning content selection}

Before speaking about the third stage, the reader should be reminded that the second stage (selecting speech materials and samples) completes the selection of the entire communicative aspect of learning content (c.f. Fig. 9). Since the selected speech materials/samples demonstrate definite meanings of language units that are functioning in those materials, it allows passing to the following (third) stage of selecting the language inventory for the learning content. It should also be mentioned that the selection of such an inventory embraces, first of all, the selection of vocabulary and, to a much lesser degree, the selection of grammar (mostly for its reinforcement and not for learning as something new and unknown). The selection of materials for teaching pronunciation is not planned at all.

In what concerns the selection of both vocabulary and grammar, the sources for such selection naturally are the selected speech materials reflecting the themes and situations represented by them. The basic criteria for doing the selection are:

1. The typicality of every particular language unit to be selected (a word, a structure, etc.) for written and/or oral communication on a given professional topic (theme) and in given professional situations, i.e., how typical it is for native speakers, specialists in a given field, to use just such a language unit in written or oral discourses/texts when writing or speaking on a professional topic in question in professional situations in questions.

2. The frequency of every particular language unit to be selected (a word, a structure, etc.) for written and/or oral communication on a given professional topic (theme) and in given professional situations, i.e., how frequently native speakers, specialists in a given field, use just such a language unit in written or oral discourses/texts when writing or speaking on a professional topic in question in professional situations in questions.

3. The explanatory potential of every particular language unit to be selected (a word, a structure, etc.) for written and/or oral communication on a given professional topic (theme) and in given professional situations, i.e., what opportunities the language unit creates for explaining the basic notions and ideas connected with the professional topic in question. 
The text about releasing feelings quoted above (5.2.2.) as an example of a typical speech material/sample for the theme "Managing Emotions and Feelings" used in teaching future practical psychologists is also a good example of a piece of written discourse on the basis of which both a part of the vocabulary to be learned and a part of the grammar material to be reinforced were selected for Unit 6 "Managing Emotions and Feelings" in the coursebook Psychological Matters (Tarnopolsky, Kozhushko, et al., 2011a). That speech sample and the others, both written and oral ones, selected for the unit served as a source of the vocabulary chosen for students' mandatory acquisition when working on the professional topic in question. The choice was made according to the three criteria above. The vocabulary selected as mandatory for acquisition comprised 45 lexical units listed below which were all assembled in the Glossary to Unit 6 placed for teachers reference at the end of the Teacher's Book attached to the coursebook Psychological Matters (Tarnopolsky, Kozhushko, et al., 2011b). The lexical units included:
1. accept
2. acknowledge
24. law of attraction
3. appreciate
25. manifest
4. attract
26. miserable
5. breathe
27. muscle group
6. chest
28. overwhelming
7. conscious
29. power
30. powerful
8. create a different reality
31. privacy
9. creator
32. progressive muscle relaxation
10. curl up
33. reassure
11. deep breathing
12. deny
34. recognize
35. reinforce
13. distract
36. release
14. empowerment
15. explore
37. responsibility
16. express
38. scream
39. self-worth
17. fulfilling life
40. source
18. happy experiences
41. supportive
19. healthy coping strategies
42. suppress
20. hit
43. take over
21. infinite possibilities and outcomes
44. tension
22. inner guidance system
23. inward
45. yell

In fact, the sample vocabulary for one unit, given above as a simple list, in the real Glossary for teachers (c.f. Tarnopolsky, Kozhushko, et al., 2011b: 163165) contains explanations of meanings of all lexical items. It is done to provide 
teachers with all the necessary references as to what meanings the students need to be taught.

The list of lexical units that is considered as mandatory for students' acquisition while working on Unit 6 (like all the other similar lists compiled by us) comprises both special psychological terms related to the theme "Managing Emotions and Feelings" (deep breathing, empowerment, law of attraction, reinforce, release, selfworth) and lexical items belonging to General English (appreciate, hit, take over). The list certainly does not cover all the vocabulary with which students work when studying Unit 6 in the coursebook. Only those lexical units are included into it that students do not know (with a great degree of probability) but which are important for the theme in question. Those lexical units that the students are very likely to know are not put into the mandatory vocabulary list - this is why the list above does not contain the names of emotions and feelings (like anger, sorrow, love, etc.) because they are supposed to be remembered by learners from their previous courses of English. But while working, on the unit allowances are made in the coursebook for giving students opportunities of reinforcing the vocabulary processed but not included in the mandatory lexical items list.

The same approach is followed when selecting grammar structures from previously chosen speech materials/samples - those structures that are planned to be reinforced in the teaching/learning process. A good example of grammatical items to be reinforced (as well as the demonstration of one of the ways of reinforcing them) can be found in one of the exercises in the Workbook to Unit 1 "Forms of Businesses" in the coursebook Business Projects for future economists and businesspeople (Tarnopolsky, Kozhushko, et al., 2002):

Write a conversation between two people who are planning to organize a partnership. The content of everything that is said has been written out for you. You need to make regular sentences of what is written. There are no modals or auxiliary verbs in the prompts. Use them wherever necessary. 'A' starts the conversation.

\section{$A$}

1. What kind of /partnership/ /you/ to have in mind?

3. What /we/ / to be going to/ do?

5. But /wel/to employ/ /a lot of staff//waiters, cooks, and others.

7. And what about /to employ/ waiters.

9. And where /we//to open/ our cafe.

11. Well, /l//to want//to think/ about it.

\section{B}

2. A partnership/two/-you and me.

4. I/suggest//to open/ a cafe.

6. Not at all. / to be//the cook/. /You/ /to know/ II/ / to bel good at /to cook/ land to lovel to do it/.

8. There/to be/ no need/. Our families/ to work as waiters.

10. I suggest /to open it/ on the bottom floor/ of your house.

/There/to be/ room enough there.

IYour house/ to bel in a good place. IAnd we / not to need/ to pay the rent. 
It can be seen that this exercise is designed to reinforce (train) the following grammatical structures in a communication-oriented learners' activity:

1. Word order in English affirmative, interrogative, and negative sentences;

2. Present forms of the verb "to be", including "there + to be" structure;

3. Present Simple tense structures (affirmative, interrogative, and negative);

4. Structures expressing future;

5. The infinitive form of verbs;

6. The gerund;

7. The modal verbs "can" and "must".

Such grammatical structures were selected for reinforcement as the most typical and frequent ones in those speech materials/samples that were chosen for the theme "Forms of Businesses" and the communicative situations matching this theme (topic): business interviewing; getting information concerning a particular company etc. (see the theme-situation matching list for the coursebook Business Projects in 5.2.1.). Besides, the selection of such grammatical structures to be reinforced at the very beginning of working on the coursebook Business Projects (Unit 1) seemed particularly important for one more reason. These structures are absolutely the fundamental ones for the grammatical system of the English language. So, recapitulating and reinforcing them during the very first classes of an ESP course is propitious for improving the grammatical accuracy of students' English communication in the course as a whole.

The fourth stage of learning content selection (selecting sociolinguistic and pragmatic information) does not necessarily follow the stage of selecting the language inventory. These two stages may, and in most cases should, go in parallel - because in both cases the selection is done from the same sources: the chosen speech materials reflecting the themes and situations represented by them. The basic two criteria for doing this particular selection are:

1. The differences between sociolinguistic and/or pragmatic aspects of communication in the target language and in students' mother tongue - if there is no difference or a great similarity, a particular sociolinguistic or pragmatic item is not taken into account at all and is not selected; the chances to be selected are the greater the greater the difference with L1 communication is.

2. The importance of sociolinguistic and/or pragmatic aspects of communication in the target language for avoiding misunderstanding or for avoiding giving offence to one's counterparts in communication - the more important the item is in that respect the more chances it has to be selected and included into the learning content. 
From the point of view of these two criteria, the dialogue between a language school representative and a potential customer at the "Languages and Cultures" Festival given above (5.2.2.) as one of the selected speech samples is important for illustrating the sociolinguistic norm of asking polite questions in the British culture. The Russian interlocutor in the conversation begins with asking his questions in full accordance with that norm, i.e., not too directly and, therefore, politely:

Could you answer some of my questions, please?

Will you please tell me where you are located?

Then, in the following questions, he reverts to a more direct Russian mode of asking questions that may seem a bit too abrupt to his British counterpart in the conversation:

How long are the courses? (It would be better to ask: "I wonder how long the courses are.")

And what about the airfare? (The alternative: "Could you let me know if the airfare is included in the price?" would sound more polite and formal)

Thus, the conversation in question can serve as a source of selecting some sociolinguistic information that is very important for students to know so as to behave properly in their own target language communication in accordance with the sociolinguistic norms.

In the same way, in what concerns pragmatic information for structuring one's communication, the conversation between a language school representative and a potential customer at the "Languages and Cultures" Festival can help in clarifying the appropriate manner of supplying the requested information in oral business intercourse. Similarly, the quoted text about releasing feeling (see in 5.2.2.) may be a source of pragmatic information about the manner of logically connecting ideas in written discourse in English and of ensuring coherence and cohesion in that discourse, etc.

The selection of the language inventory and sociolinguistic and pragmatic information to be taught to students finalizes the selection of learning content in accordance with the linguistic aspect of that content and completes the third and fourth stages of selection. That allows passing to its last, fifth, stage which is focused on the psycho-physiological aspect of learning content selection: the selection of communication and language skills to be taught and learned for developing students' communicative competence.

\subsubsection{The fifth stage in learning content selection}

In what concerns the language skills to be taught, their selection fully depends on the chosen language inventory.

For example, all the lexical units that were listed in 5.2.3. as belonging to the mandatory vocabulary on the theme "Managing Emotions and Feelings" 
selected for the ESP course designed for future psychologists are supposed to be acquired by students in such a way as to be included into the overall structure of their lexical skills. This means that learners are expected to recognize and understand them with no difficulty when reading or listening, and mostly subconsciously, i.e., without special efforts for remembering, use them in their own oral or written speech (speaking and writing). The same concerns all grammar items listed in 5.2.3. as grammatical material for recapitulation and reinforcement when working on the first theme "Forms of Businesses" in the ESP course for students of Economics and Business.

In fact, no special selection is needed for determining what language skills students are expected to develop. The lists of such skills totally depend on the language inventory lists compiled for every particular ESP course. Since such inventories may be different for different content-based ESP courses (depending on students' majors, the peculiarities of their future professions, etc.), the language skills taught in a variety of ESP courses may also vary rather broadly.

The situation with selecting communication skills is different in certain respects.

On the one hand, the skills to be selected depend on the sociolinguistic and pragmatic information chosen for teaching and learning. For instance, it is clear from those items of selected sociolinguistic and pragmatic information which were given in 5.2.3. that for oral communication in English students majoring in Economics and Business need to develop the sociolinguistic skills of asking polite questions when speaking in a formal (official) situation, as well as the pragmatic skills of supplying orally the requested information through appropriate language means. This requirement follows from the sociolinguistic and pragmatic information items selected for such students from the sample conversation at the Festival "Languages and Cultures" (c.f. 5.2.3). For written communication in English, the students majoring in Psychology need to develop the pragmatic skills of logically structuring the texts that are being written and of making such texts united, coherent, and cohesive (also by using relevant language means). This latter requirement follows from the pragmatic information selected from the sample text about releasing feelings (c.f. 5.2.3).

In all such cases, the selection of communication skills to be taught and acquired is no more difficult than the selection of language skills on the basis of the selected language inventory. Students are expected to develop all communication skills that are based on the sociolinguistic and pragmatic communication norms demonstrated through the inventory of sociolinguistic and pragmatic information items selected for teaching and learning.

However, students must also develop other communication skills. They are connected not to the sociolinguistic or pragmatic communication norms but 
to the requirements of professional communication in the target language that specialists may be involved in when engaged in their professional activities. Such skills are the specific skills of reading, speaking, listening, and writing for professional purposes in the target language, and they have to be adapted to the specificity of professional tasks solved by specialists.

When compiling the list of those skills to be taught to future economists and businesspeople (in the process of preparing the coursebook Business Projects), we interviewed, during the years $1996-1998$, forty specialists in that field. All the interviewees were oriented in their professional activities at working with foreign partners, so they all knew English and quite frequently used it in their work. The interviewing was done on the basis of questionnaires that comprised the lists of possible skills to be developed. The interviewees were asked to comment on those skills of which they felt the greatest need in their professional work requiring the use of the target language and to add whatever other skills they deemed to be important.

Among the most important reading skills for them they named skimming (for finding what the texts that they were planning to read were about and whether they needed more detailed reading and understanding of them) and scanning (for full understanding of all the principal information in the texts being read while skipping the information of secondary importance). This is why they especially valued the skills of being able (a) to find the main idea(s) in the text as a whole and in its separate paragraphs; (b) to make logical connections between elements and parts of the text; (c) to determine what information in the text is of primary importance and which one is of secondary importance to be able to skip it; (d) to find in the entire textual information some particular (required) information as fast as possible, etc. On the other hand, the interviewees were very little interested in the skills of reading professional texts very attentively and thoroughly from the beginning to the end with the aim of understanding absolutely every smallest item of information in them. That was believed to be hardly applicable to their professional reading in English as a foreign language. So, top-down reading techniques were much more highly valued than bottom-up ones. In fact, it can be seen that the interviewees' requirements as to reading skills to be developed by ESP students coincided with what the experts in teaching reading in English as a foreign language have actually been recommending for decades (Dubin, 1986; Grabe, 1986; Carroll, Devine, \& Eskey, 1988; Kellermann, 1981; Nuttal, 1996; Silberstein, 1994).

The target language oral communication skills (speaking and listening skills listed together as being parallel) that our interviewees considered to be the most important for them included: 


\section{Speaking skills}

Orally supplying in English business and economic information in various situations of business intercourse

Business telephoning in English to partners, suppliers, customers, clients, etc.

Interviewing in English partners, suppliers, customers, clients, etc.; making inquiries with the aim of obtaining some specific required information.

Negotiating in English on business issues with partners, suppliers, customers, clients, etc.

Discussing/debating business and economic issues in English.

Delivering in English presentations on business and economic issues.

Conducting job interviewing in English and/or participating in such interviewing as an applicant for a job.

\section{Listening skills}

Understanding business and economic information that is being supplied orally in various situations of business intercourse

Understanding telephone calls in English from partners, suppliers, customers, clients, etc.

Understanding in all details when being interviewed in English on business and economic issues or when having to answer inquiries on those issues.

Understanding in all details what is being said by partners, suppliers, customers, clients, etc. in the process of negotiating in English on business issues.

Understanding in all details what is being said in the process of discussing/debating business and economic issues in English.

Understanding presentations on business and economic issues delivered in English.

Understanding in all details what is being said/inquired in English in the process of job interviewing.

Understanding business news and programs in English broadcast over the TV and radio.

(It should be explained in brackets that the last listening skill - understanding business news and programs - was something not foreseen by us. It was added by 19 interviewees out of 40. Due to the addition of that last skill, the item "Business News" was included into the audio materials to the coursebook Business Project - to train students in listening to such specific kinds of information in English. For those audio materials, fragments of authentic business news and programs were selected and recorded - to be processed and re-recorded later, see Chapter 4 - but only those ones that were not firmly attached in what was 
said to some specific time periods which would make them impossible to be used after that period had elapsed. An example can be given in the tapescripts of two fragments below which originate from an authentic Deutsche Welle program of 2002. The considerably modified fragments of that program continue each other and are used in the audio materials for the coursebook Business Project for business news listening tasks in two classes when working, first, on Unit 3 and, later, on Unit 4:

\section{The History of the Euro's Coming Into Europe}

The year 2002 saw the replacement of the national money in a number of European countries with one international currency. It was the year when the Euro came into Europe. It's interesting to remember how such a radical step as replacing national currencies was made. How long did the transition periods last? In twelve European countries all cash transactions started to be made in Euros as of January 15,2002 . But national currencies were still usable up to a certain date to make the transition smoother and less painful. There were both economic and psychological reasons for this. Among them was the fact of some opposition to the Euro in a number of countries where the population found it difficult to switch and get used to new money.

\section{The History of the Euro's Coming Into Europe (continuation)}

The transition period, that is the period of double circulation when both the Euro and the national currencies were used, differed from one Euro zone country to another. Germany was the fastest. The mark's last day was December 31, 2001. But companies went on accepting the mark up till the end of February 2002. The Netherlands took the guilder out of use at the end of January 2002. It was followed by Ireland's pound on the 9th of February 2002. France waited until the 17th of February 2002, while the other countries concerned said good-bye to their currencies at the end of February. But if you didn't manage to spend the last of your national notes and coins in the double circulation period, you could still exchange them at your regular bank. But there were date limits at the banks, too. Germany was fast again and banks there stopped exchanging at the end of February 2002. The French, Irish, Spanish, Portuguese, and Luxembourgers could exchange till the end of June 2002. The Dutch and Belgians had time till the end of that year. But even after the latest date, the central banks continued exchanging. And it was the central banks who were responsible for destroying the old cash.

The tasks that were done by the students on the basis of listening to such fragments were: 1) discussing what was heard in pairs or small groups, which helped the teacher to check whether the fragments were adequately understood; 2) role playing interviews on the basis of news heard; 3) supplying learners' own items of business news - all of which helped in acquiring the skills of full comprehension of broadcast business news and programs in English.) 
In what concerns the skills of writing in English for professional purposes, the interviewed specialists in Business and Economics selected the following ones:

- writing business letters and emails;

- compiling in writing business contracts and agreements;

- writing the notes of presentations and full texts of them (to orally deliver those presentations later):

- taking notes of presentations made by other people; taking notes in the process of business meetings, negotiations, etc:;

- writing reports on the work done (like in joint projects):

- writing different kinds of instructions;

- writing in message/note pads, i.e., taking telephone messages in writing.

It is interesting to note that, when we were selecting - in quite an identical manner (21 interviewees) - the communicative skills to be taught to students majoring in Psychology, the results obtained were substantially different:

1. The smallest difference was observed in what concerned the skills for reading in English. Actually, the only difference was a much greater interest in being able to read professional texts very thoroughly and attentively to understand all details - which was deemed to be necessary for reading professional (scholarly) articles, cases, and reports. All the other required skills were the same.

2. In speaking and listening the differences were much more easily observable. Telephoning skills and skills for listening to radio/watching TV programs were not required at all, while negotiating skills were much less valued. On the other hand, skills connected with interviewing (like during psychological sessions), presenting and reporting (like at professional conferences and seminars), discussing/debating professional issues were in much greater demand than with the economists and businesspeople. At the same time, the skills of supplying information, inquiring for information and corresponding listening skills were equally valued.

3. In writing, quite naturally, the skills of compiling contracts and agreements and taking telephone messages were not in demand at all. Equally required (as compared with the economists and businesspeople) were the skills of writing notes of presentations and full texts of them to orally deliver those presentations later at psychological conferences and seminars, as well as the skills of taking notes of presentations, reports, and, especially, lectures on professional issues being delivered by colleagues. The same concerned writing reports on the work done and, what seemed a little surprising to us, writing formal letters and emails. What was absolutely different from the requirements of economists and businesspeople, was the need to learn how to write notes, summaries, and abstracts of what has been read in English, as well as summaries and abstracts of one's own papers, and even (9 interviewees out of 21) short articles in English. 
As can be seen from above, in content-based instruction future psychologists need to be taught different communication skills as compared with future economists and businesspeople. With the difference in language inventories, speech materials and samples, themes and situations of professional communication, this means that the learning content in a content-based ESP course for future psychologists greatly differs from the learning content in a content-based ESP course for students majoring in Economics and Business. And it is going to be the same for each of the two randomly chosen specialties in which our students major and which we choose for analysis. So, in content-based instruction the learning content in ESP courses is totally dependent on students' majors and will inevitably be quite different for different majors.

Therefore, the purpose of the last several sections in this chapter (see all the sections in 5) was not to supply the full learning content for ESP teaching to students of just two majors: Economics and Business and Practical Psychology - those were nothing more than practical examples. Its purpose was supplying the complete practical procedure of rational, well-grounded, accurate and precise selection of ESP learning content for whatever content-based ESP courses designed for ESP tertiary students of all majors.

Having finished the description of that procedure, we could finish this chapter with it - but for one important question. This is the question of ESP teachers who are not and cannot be specialists in all of students' majors. If in content-based instruction the learning content is very closely connected and fully dependent on the content matter of students' majoring disciplines and their future professional activities, the question arises how ESP teachers can cope with such content. This question is discussed in the last part of the chapter.

\section{Preparing ESP teachers for teaching in content- based ESP courses for tertiary students}

Preparing teachers for teaching ESP in programs where not only the language but the extra-linguistic professional content is in the focus of attention is one of the difficult issues that hinder the successful and comprehensive introduction of such programs (Coyle, 2007; Stoller, 2007). Due to this, some authors even express doubts as to the possibility of effectively using CLIL (Pugliese, 2011). These doubts spread to content-based instruction too, which is, as it is clear from what has been said earlier, a twin sister of CLIL.

Most certainly, such doubts are grounded in what concerns the English immersion programs where the greatest difficulty with the teachers arises.

In one of our previous works (Tarnopolsky, Momot, et al., 2008), it was shown that classes in immersion programs at tertiary schools cannot be taught by ESP 
teachers. It should only be specialists in a given field of knowledge because, otherwise, even if the level of English is good, the level and standard of teaching the majoring/professional discipline is inevitably going to suffer.

If we exclude the cases when such disciplines are taught by native speakers of English, specialists in a given field, working in English immersion programs at tertiary educational institutions in non-English-speaking countries (not an infrequent case in today's Europe but the one that is beyond the scope of our analysis), there are only two possible options left:

1. The first and the best option is organizing the teaching of English immersion programs at tertiary schools by teachers with dual higher education: one in the field of languages (a certified teacher of English) and the other in the field of some of students professional/majoring disciplines. Nowadays, it is not an infrequent situation, at any rate, at Ukrainian tertiary schools - for instance, at Alfred Nobel University in Dnipropetrovsk five ESP teachers have both higher education in Economics and higher education in the field of English language teaching Naturally, they are the best candidates for teaching in English immersion programs and are actively engaged in such programs.

2. The second option is employing teachers, specialists in a given field, with a high level of command of English that allows them teaching classes in their specialty in this language. That level should not be lower than C1 (Council of Europe, 2001) because, otherwise it is hard to expect a sufficient linguistic standard of classes taught in English. This alternative is possible but worse than the first one because the sufficient level of potential teacher's English has to be confirmed - for instance, with a certificate of successfully passing a CAE or an IELTS exam. Besides, a professional teacher of English should also be included in the program to control and check the adequacy of its language component.

However, the problem and difficulty of finding an adequate (both in what concerns the language and in what concerns the discipline's content matter) teacher for an English immersion program loses its acuteness when the choice of such a teacher should be made for a content-based ESP course planned to be taught during students' junior years of university's studies (like the second year of such studies which is the case for practical examples given in this monograph). It may be said that in such situations it is more of a pseudo-problem.

Of course, even here, like in immersion programs, the teacher with dual higher education (English and its teaching and some other field corresponding to students' majors) would be the best option. But even if this is impossible, it should be remembered that, unlike immersion, which is a course of a certain discipline (first) taught in English (second), a content-based ESP course is in the first place a course of English and only in the second place a course modeling some professional discipline(s) through the medium of the target language. This 
is why this course must be taught by a professional teacher of English and by no one else. As to preparing such teachers for the requirements of content-based instruction, it should be taken into account that such preparation is not too difficult and will not take much time.

First, this is because, as already said, content-based ESP courses are designed for students in their junior years of university studies, i.e., for those students who do not have too much knowledge of their future profession as yet. That is why content-based ESP courses embrace only the basics of that profession accessible and comprehensible to educated laypeople - both the students and the teachers. The ESP teachers in this case do not need to be specialists in a given field - the basic professional content matter embraced by whatever content-based ESP coursebook will be quite understandable to them, and they are not going to feel the necessity of going beyond such basics into more specific and technical details of students' future specialty.

Second, it should be remembered that during their teaching careers ESP teachers, as a rule, specialize in teaching English for Specific Purposes mostly only in certain fields of knowledge - Business, or Technology, or Medicine, or whatever other field - and are always reluctant to change that field. Such content-based specialization of ESP teachers that naturally happens is a great help in introducing content-based ESP instruction. If content-based ESP instruction for future economists and businesspeople is being dealt with, there are always enough ESP teachers who for years have been teaching Business English to just that category of students and who have acquired enough knowledge of Economics and Business during their careers to make a relevant content-based ESP course no problem for them in what concerns the content matter of that course.

Finally, since what we are discussing is content-based ESP courses at tertiary schools where ESP teachers work in the professional surrounding of specialists in their students' majors, there cannot be any problems in organizing short courses on certain specialties specifically for such ESP teachers even before they start teaching their content-based ESP courses - to help them cope with the professional basics of those courses.

Therefore, it may be asserted that the issue of preparing ESP teachers for teaching in content-based ESP courses is not an insurmountable problem at all and it can be successfully solved by every higher school. 


\section{Conclusion to Chapter 2}

In this chapter the notion of content-based instruction, as the second (after experiential interactive teaching/learning) fundamental notion of the constructivist approach to designing ESP courses at tertiary schools has been analyzed. The definition of content-based instruction has been given, and it has been shown that the adequate implementation of the constructivist approach is impossible without both the experiential interactive teaching/learning and the contentbased instruction taken in their integral unity. The characteristics of this integrated experiential interactive content-based ESP teaching/learning have been discussed as the only possible full practical embodiment of the constructivist approach to designing ESP courses at tertiary schools.

A version of content-based instruction, such as CLIL, has been analyzed with demonstrating that it is a broader notion than content-based instruction, the latter being meant for ESP courses at tertiary schools only. Also, an analysis of English immersion courses has been made as an approach closely related to content-based instruction that may continue it during the senior years of students' university studies. The manner of gradual transition from content-based ESP courses to English immersion in courses of students' majoring/professional disciplines in the senior years of their university studies has been substantiated.

The organizational forms of content-based instruction have been considered, and theme-based instruction has been demonstrated as an optimal form of it for ESP courses during the junior years of students' university studies.

Five component parts of learning content for a content-based (theme-based) ESP course have been determined and the five-stage procedure of selecting this content was described, with every stage of selection discussed in detail using appropriate examples.

Finally, some ideas concerning preparing teachers of English as a foreign language for teaching in content-based ESP courses have been formulated.

Everything said in the first and second chapters about experiential interactive teaching/learning and content-based instruction as the fundamental constituent parts of the constructivist approach to designing ESP courses for students of tertiary educational institutions allows proceeding to analyzing the third, last, of such basic constituents subordinated to the first two. It is blended learning discussed in the next chapter. 